\title{
Interactions between Ideas and Behaviour in Organisations
}

\author{
DOI: 10.12776/QIP.V20I2.755 \\ Magnus Marmgren, Sverker Alänge, Stefan Book
}

Received 26 June 2016, Revised 19 July 2016, Accepted 13 September 2016

\begin{abstract}
Purpose: To develop and test a framework which can be used to facilitate the understanding of how ideas interact with behaviour in organisations, in ways that have practical relevance in organisational development and improvement.

Design/methodology/approach: The framework proposed in this paper is the product of an abductive research process. This process involved testing and reflecting in action, and on action when writing. The emerging framework was also challenged by theoretical input from continual literature studies and has (at different stages of its development) been part of the theoretical framework for a $\mathrm{PhD}$ dissertation, research articles and master's theses.
\end{abstract}

Findings: The framework graphically highlights the relationship between explicit (i.e., spoken or documented) and tacit ideas, and that the latter is what largely controls action. It also implies that for new explicit ideas or theories to become effective, they have to become part of the tacit guiding ideas. This is often difficult to achieve. The framework gives a perspective on why this is the case and how it can be counteracted, including by: addressing the coherence between its parts; supporting sense-making; and seeing development as iterative and contextual.

Practical implications: The framework has been tested with practitioners and has rapidly assisted professionals in making explicit, and developing, tacit knowledge. It has also been successfully used in analyses in several papers, including studies of sustainability and process management.

Originality/value: The implications of the framework are in line with existing research, yet we believe that the graphical model adds both scientific and practical dimensions. This is partly due to the framework making it easier to differentiate between complex concepts that are often confused.

Category: Conceptual paper 
Keywords: Conceptual framework; tacit guiding; change management; sustainability; naturalizing

\section{INTRODUCTION}

Organisations continuously renew themselves by absorbing and (re)creating new ideas (Alänge and Steiber, 2011). This can happen independently of management, but is also often the result of a strategic decision to 'implement' or 'adopt' a certain concept and the ideas related to it. The application of such concepts in change projects often does not give the intended results (Keating et al., 1999; Beer, 2001), as associated ideas are not naturalized as part of a process leading to genuine change and improvement (Book, 2006). Instead, the changes achieved from such projects are often both inefficient and transient.

There are various reasons indicated in the literature. One reason is the inertia of knowledge and competence (Alänge, Jacobsson and Jarnehammar, 1998), though it also depends on the way improvement projects are carried through (Nadler and Tushman, 1997). Another reason, raised by Book (2006), is the risk of focusing on work 'in theory' that is not sufficiently connected to improvement 'in action'. An example of this is focusing too much on process maps and procedures as opposed to cultivating change in behaviour. Lack of clarity in language (e.g., calling both process maps and actual ways of working 'processes') and associated lack of clarity in focus risk reinforcing this tendency (Book, 2006).

This paper presents a conceptual framework which can be used to facilitate the understanding of how explicit and tacit ideas interact with behaviour in organisations in ways that have practical relevance in organisational development and improvement. The framework can act as a 'sensitising device' (Weick, 1976, p.2) to provide a better understanding and new perspectives on organisational change, as well as to clarify related terminology. It can also function as a communication and planning tool for ongoing change and learning processes.

The framework is the product of an iterative and abductive process and builds on a combination of experience from the field and theories/ideas. Four central theoretical contributions come from Argyris and Schön (1996), Weick (1995), Kahneman (2011) and Nonaka (1994). In this article, the framework will be described, and its usefulness analysed and illustrated through practical cases.

\section{METHOD}

The research follows an abductive logic (Dubois and Gadde, 2002) where empirical data from various company cases meet theories and an emerging theoretical framework in an iterative learning process. It can be described as a kind of 'first-person action research' process in line with Lifvergren (2013), based on the authors' experiences. It started in a learning alliance (Frischer, 2006), in which Marmgren and Book, based on their respective 
preunderstandings (Gummesson, 2000), were searching for a shared understanding of naturalization processes where improvement takes place within and among organisations. One starting point was the realisation that there was a need to understand why there frequently seemed to be a large discrepancy in organisations between what was written, what was said and what was actually done. An effect of this search was the invitation of Alänge into the learning alliance, and the subsequent initiation of more systematic research as part of a doctoral process for Marmgren. Then, a more theory-driven development started involving sense-making (Weick, 1976) when writing articles as well as sensemaking in action, when driving organisational change. The observations from consultancy practice and earlier research (e.g., Book, Alänge and Solly, 2004; Book, 2006) made us select a research approach where we initially re-analysed earlier empirical data and simultaneously developed our theoretical understanding by testing and refining our initial theoretical model.

The early version of the model was developed based on our pre-understanding (Gummesson, 2000) from practice, earlier research and literature studies in the area of learning and behavioural change in organisations. Specifically, observations concerning ambiguous uses of concepts both by practitioners and researchers stimulated the development of a first version of a framework aimed at making a distinction between the complex reality and what could be distilled into a document. In order to test this framework, we initially used empirical data from Book's PhD process (2006) and made a reanalysis of the TQM-based change process at Fagersta Stainless AB from 1984 to 1999 (Marmgren, Alänge and Book, 2012). The authors assumed complementary roles on a scale from insider to outsider, which can be beneficial for research (Alänge and Mellby, 2006; Brannick and Coghlan, 2007), as it provides additional opportunities for reflection and triangulation. In parallel, according to the chosen abductive approach, the empirical findings were discussed relating to literature. The result of the first article (Marmgren, Alänge and Book, 2012) was the development and initial verification of the framework.

According to the abductive logic chosen, in our next phase of systematic combining (Dubois and Gadde, 2002), a literature review was conducted. The first outline of the model had been built based on our preunderstanding; this time, the intention was to make a thorough review of earlier research on the subject area, and specifically the understanding of subconscious or tacit knowledge dimensions. This included going back to classical writers on management and on understanding the role of intuition, values, routines and more hidden assumptions and tacit knowledge components in decision-making and change processes (Schumpeter, 1934; Barnard, 1938; Polanyi, 1966; Argyris and Schön, 1978, 1996; Nonaka, 1994; Kahneman, 2011).

This abductive way of iterating between empirical and theoretical phases has been described as a heuristic spiral (Gummesson, 2000) where the conceptual framework itself is being refined in parallel to the development of empirical understanding. 
Next, followed a period when the framework was tested in a number of practical settings in order to verify its validity in consultancy practice by co-authors Book and Marmgren (Gummesson, 2000; De Guerre, 2002), as well as in further research (Clancy, 2014; Book, Marmgren and Gustafsson, 2014; Alänge, Clancy and Marmgren, 2016). It was found that the framework made sense for practitioners who commented that the framework provided new insights regarding an area that they had earlier perceived familiarity with. Hence, these practical tests contributed to improving our understanding of the usefulness of the framework and its ecological validity.

The authors have approached the task from a constructionist perspective aiming at developing a framework that can provide value both for practitioners and academics. The intention has not been to develop the ultimate and general framework; rather, the approach has been to develop a framework that can be used for various analyses and that can also be modified to meet specific analytical needs. Early on, the strength of visual communication was acknowledged, as well as that the framework in its graphical simplicity supports 'visual ambiguity' (Worren, Moore and Elliott, 2002), stimulating different interpretations and thereby also the development of the framework. Different versions of the framework model have been used for direct communication and verification both of analysis content and of the model itself.

Based on a constructivist stance and analytical generalisation of our extensive experience of using it, we believe that the framework can be useful in analysing any type of organisation.

\section{THEORIES ON THE INTERACTION OF IDEAS AND BEHAVIOUR}

The starting point in our search for a useful framework was our practical experience working in and with organisations, and our observations in earlier research studies. We sensed that leaders were often having problems in trying to use management ideas ${ }^{1}$ to influence the behaviour of individuals and groups in organisations. What leaders say and what is documented do influence to some extent, but the processes of naturalisation are often problematic (Book, 2006). Hence, ideas which could be productive often do not become a natural part of thinking and acting in a productive way.

\footnotetext{
${ }^{1}$ Ideas can be understood as related sets or structures in constant dynamic/interaction, which are also affected by external influences. This is in line with Barley (1986) who write that 'Structure can be viewed simultaneously as a flow of ongoing action and as a set of institutionalized traditions or forms that reflect and constrain that action'.
} 


\subsection{Underlying mechanisms}

The underlying mechanisms influencing the process towards a successful use of the management ideas are often complex and poorly understood. Furthermore, these mechanisms are often difficult to clarify and problematic to address in order to gain positive results from the use of the ideas. Another challenge can be to identify and expose ideas that have a strategically poor fit with the organisation at hand. One idea may be good in one organisation yet not in another (Alänge, Clancy and Marmgren, 2016). So what we were striving for was to better understand and explain an important issue in many organisations. This issue concerns the interaction between ideas and behaviour, among individuals and groups in organisations, on the way towards improvement.

This issue is not new and over the years there have been important contributions that have been forgotten or maybe not fully understood. Thus, as a first step, we went back to previous literature, starting with two classical writers on management and change. What is guiding individuals are not only explicit instructions and analytical thinking, but also what has been expressed as intuition, subconsciousness and culture. That our behaviour is not mainly guided by conscious decisions or rules, but by something more tacit was stated early on by Schumpeter (1934, pp. 63-64), who writes:

Every man would have to be a giant of wisdom and will, if he had in every case to create anew all the rules by which he guides his everyday conduct... This is so because all knowledge and habit once acquired becomes as firmly rooted in ourselves as a railway embankment in the earth. It does not require to be continually renewed and consciously reproduced, but sinks into the strata of subconsciousness. It is normally transmitted almost without friction by inheritance, teaching, upbringing, pressure of the environment. Everything we think, feel or do often enough becomes automatic and our conscious life is unburdened of it.

Barnard (1938, pp. 302-303) differentiates between 'logical' processes 'conscious thinking which could be expressed in words, or other symbols, that is, reasoning', and 'non-logical' processes that '...are not capable of being expressed in words or as reasoning, which are only made known by a judgement, decision or action. This may be because the processes are unconscious, or because they are so complex and rapid, often approaching the instantaneous, that they could not be analysed by the person within whose brain they take place'. Barnard argued that the latter's significance was, 'obscured by the general belief that reasoning indicates a higher order of intellect than do the non-logical processes underlying quick judgement'. According to Barnard (1938, p. 305) these processes, 'run all the way from the unreasoning determination not to put the hand in the fire twice, to the handling of a mass of experience or a complex of abstractions in a flash', and he stresses that 'we could not do any work without this type of mental process' that is so unexplainable that it goes 
under many names, such as intuition, good judgement, inspiration, stroke of genius, common sense, and more.

Several years later the Nobel Prize laureate Kahneman (2011) presented theories that show many similarities to the two earlier researchers' empirically based observations. The subconscious and effortless thinking that governs most decisions made by an individual, Kahneman (2011) refers to as System 1: This fast thinking includes two variants of intuitive thought, the expert and the heuristic, as well as the entirely automatic mental activities of perception and memory' (Kahneman, 2011, p. 13). The 'expert intuition' is what Herbert Simon identified as a form of recognition, when an expert is able to access information stored in the memory to analyse a new situation (Simon, 1992). The essence of 'intuitive heuristics', on the other hand can, according to Kahneman (2011, p. 12), be explained as 'when faced with a difficult question, we often answer an easier one instead, usually without noticing the substitution'. Tversky and Kahneman (1974, p. 1) state that 'In general, these heuristics are quite useful, but sometimes they lead to severe and systematic errors'.

Kahneman also introduces System 2 which refers to a slower, conscious and more attention-demanding and effortful form of thinking. The System 2 way of thinking has an important role for correcting and setting direction, and also for consciously analysing new situations or problems, though it is not functional as a general way of thinking/deciding, because it is much slower and uses a considerable amount of resources; in other words, it can be 'depleted' when used.

\subsection{Learning processes shaping behaviour}

The focus of the conceptual framework is on the role of ideas, theories, management models and organisational innovations which can guide learning towards new behaviour in organisations. What is included in an organisational innovation or in a management model differs, but ideas and theories can be seen as the basic building blocks (Weick, 1995). Thus, a starting point could be to discuss the issue from the perspective of ideas/theories and sets of ideas/theories. Sets of ideas/theories can exist on many levels in an organisation. They exist at an explicit level, which corresponds to what Argyris and Schön (1996) call 'espoused theories'. Sets of ideas also exist at a tacit level that normally guides action, which they call 'theories-in-use.' This is in line with the thinking of Schumpeter, Barnard and Kahneman as described above.

According to Argyris and Schön (1996), an individual is normally not aware of which are his theories-in-use, and can typically only become aware to a limited extent, and even then with substantial effort. This can happen through 'doubleloop learning,' when efforts are made to deeply reflect upon a situation, including questioning its basic assumptions. If double-loop learning is in use, there is a possibility to go beyond what people express (and mostly also believe in themselves) and go deeper and get in contact with the actual theories-in-use, which then can be questioned and transformed or just be made aware of. Argyris 
and Schön (1996, pp. 20-21) contrast this deeper learning with the more common single-loop learning, which can be seen as a regular adjustment, as with that of a thermostat.

There are similarities in between these theories, but there are also differences reflecting their origin and use. Kahneman (2011, pp. 39-43) observed that both cognitive efforts and self-control are forms of mental work that compete for the limited resources available for the System 2 way of thinking. However, sometimes people can spend considerable effort for longer periods of time without having to exercise conscious self-control, a state that Csikszentmihalyi (1990) named 'flow'. So, while Kahneman (2011) primarily refers to the depleting effort of self-control and the substantial resource use that limits the System 2 way of thinking, Argyris and Schön (1996) primarily emphasize that the individual is often not even able to identify his/her own theories-in-use, primarily due to different kinds of defence mechanisms. On an organisational level, the theory-in-use might remain tacit because it is either 'indescribable' or 'undiscussable' (Argyris and Schön, 1996, p. 14). But in line with Schumpeter and Barnard, the similarity between 'theories in use' and 'System 1' is that they are subconscious, fast and follow a rule of least resistance.

\subsection{Towards the conceptual framework}

The above lines of thought are also in line with Polanyi's and Nonaka's use of tacit and explicit knowledge. Polanyi (1966, p.4) classified human knowledge into two categories, explicit (or codified) and tacit. Explicit refers to knowledge that is transmittable in formal systematic language. Tacit knowledge however, '...has a personal quality, which makes it hard to formalise and communicate. Tacit knowledge is deeply rooted in action, commitment and involvement in a specific context' (Nonaka, 1994, referring to Polanyi). Nonaka (1994) develops Polanyi's concepts, claiming that tacit knowledge involves cognitive and technical elements. The cognitive elements centre on 'mental models' (JohnsonLaird, 1983) formed 'by creating and manipulating analogies in their minds'. These models include 'schemata, paradigms, beliefs and viewpoints'. The technical elements cover 'concrete know-how, crafts and skills that apply to specific contexts'. We will use the term 'Tacit guiding' which relates closely to tacit knowledge, theories in use, and the subconscious thinking of System 1.

We will also use the term 'Explicit thoughts and ideas' which relates to explicit knowledge, espoused theories and to the conscious thinking of System 2, and can mainly be observed and shared when spoken and/or documented ${ }^{2}$. Explicit ideas might have more or less support by (the people in) the organisation/unit in focus. According to Barnard (1938, p.163), 'the decision as to whether an order has authority or not lies with the persons to whom it is addressed', and their

\footnotetext{
${ }^{2}$ Unspoken explicit ideas might also be important. One example could be when they have an external origin, e.g., from a common culture, but for some reason are not spoken out loud, as in an intercultural setting. Another might be when behavior sparks ideas that are not spoken of or documented.
} 
decisions are based on: if the order can be understood; if it is perceived as not inconsistent with the purpose of the organisation; if it is compatible with their personal interests; and if it is at all possible to comply with. This means that the eventual impact of 'Goals imposed from the top... depend on willing compliance from the bottom'.

Explicit thoughts and ideas (even accepted ones) might however have a limited impact on behaviour if they are not naturalised (Book, 2006). Weick (1976, p.4) posed a similar argument that: 'Given a potential loose coupling between the intentions and actions of organisational members, it should come as no surprise that administrators are baffled and angered when things never happen the way they were supposed to.' Similarly, March and Olsen (1976) stated that, 'individuals' goals and intentions may be only loosely coupled to their actions', and Argyris and Schön (1996) emphasized that there often is a systemic mismatch between explicit espoused theories and tacit theories-in-use and that 'An organisation's formal documents, not infrequently contain espoused theories of action incongruent with the organisation's actual pattern of activity.' Meyer and Rowan (1977) also questioned the rational-organisation perspective with formal structures (explicit ideas) purposefully designed to produce results. They argued that formal structure also originates from myths embedded in the institutionalised environment.

From an organisational culture perspective, Schein (1984) shows that what is possible to observe are only the artefacts, for example the physical objects, the way the company is organized, and so forth, as well as what is expressed as espoused values. An organisational culture's underlying basic assumptions (tacit ideas with our terminology) are harder to identify, especially so when it comes to moral values, which are ingrained already at childhood and become very close to the individual's personality (Friberg, 1975, 1976); an organisational culture is built on other cultures (e.g., national cultures). There are obvious similarities between Argyris and Schön's organisational learning theory and Schein's organisational culture theory, in terms of espoused values and espoused theory; moreover, in both theories the complication is that what is espoused does not always reflect what is really influencing behaviour. However, the importance of culture and values to guide behaviour in organisations has been noticed, especially when it comes to organisations trying to unleash creativity among its employees (Tushman and O'Reilly, 1997). Some organisations have even purposefully designed their management systems to rely on culture as the most powerful means for guiding creative individuals (Steiber and Alänge, 2013, 2016). For an organisation to function effectively however, there should be a relative coherence in what you say, write and do ('walk the talk') i.e., in the different parts of the framework to be described below (Alänge 1992; Marmgren, Alänge and Book, 2012) ${ }^{3}$.

\footnotetext{
${ }^{3}$ Brunsson's (1982) use of ideologies captures many items categorized as accepted ideas and tacit guiding when there is coherence, and demonstrates how ideologies then guide action.
} 
Behaviour is also influenced by various other factors, including the restrictions or autonomy created by technology (Karlsson, 1979) and the actions of internal or external stakeholders (e.g., customers). To change behaviour within the same boundary conditions, you have to change either the ideas or the technology (i.e., production line, IT system, etc.) that govern behaviour. If technology is changed in conflict with existing ideas, this change is, however, likely to cause resistance (Argyris and Schön, 1996).

\section{CONCEPTUAL FRAMEWORK}

From our theory review, it is evident that both tacit and explicit ideas need to be treated if we want to understand the process of influencing behaviour. In our framework, the focus is on the influence of thoughts/ideas/theories on behaviour, and differentiating between explicit and tacit thoughts/ideas/theories (i.e., we do not visualise the influence of e.g., technology). This line of thought produces the couplings visualised in Figure 1:

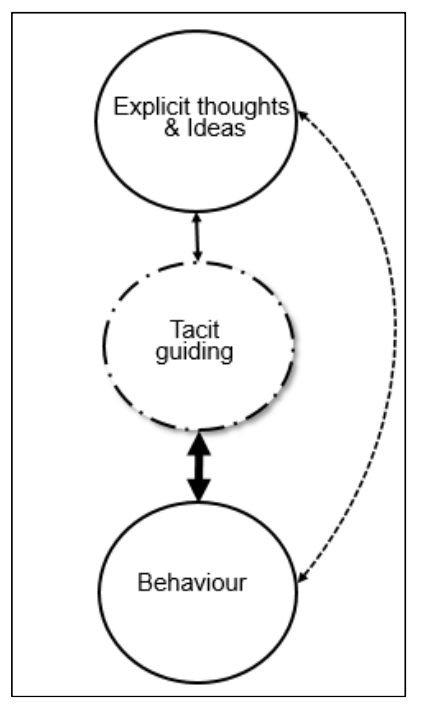

Figure 1 - Interaction between explicit ideas, tacit guiding and behaviour

The dotted line illustrates the normally relatively weak relationship between explicit ideas (normally spoken or documented) and behaviour. The thick solid line indicates the strong connection between the subconscious tacit guiding and behaviour, and that this is normally the key to sustained behavioural change. The broken line surrounding 'Tacit Guiding' indicates that it is not directly observable in the way that behaviour or explicit ideas are.

The interaction shown in the figure relates closely to Nonaka's (1994) concepts of externalisation (tacit to explicit knowledge) and internalisation (explicit to tacit knowledge), with the difference that behaviour is not part of Nonaka's model. For example, Nonaka's concept of socialisation (tacit to tacit knowledge) 
in our model would also include the interaction with behaviour. We believe that this adds some clarity and explanatory aspects.

Our experience from organisational change projects has shown that looking at the difference between what is spoken and documented can provide interesting insights into the dynamic of an organisational change project, such as a change in the management system (Marmgren, Alänge and Book, 2012). Figure 2 presents the framework with explicit ideas shown through their manifestations as spoken or documented. The dotted lines illustrate the normally relatively weak relationship between what is spoken or documented and behaviour. The thin solid lines indicate the strength of the relationship between what is spoken and what is documented and also their links to the tacit guiding, which all can vary in strength. The thick solid line still indicates the strong connection between the subconscious tacit guiding and behaviour; that tacit guiding strongly influences behaviour, and vice versa: that behaviour has a strong impact on tacit guiding as when, for example, top managers behave in accordance to what they 'preach' (spoken and documented).

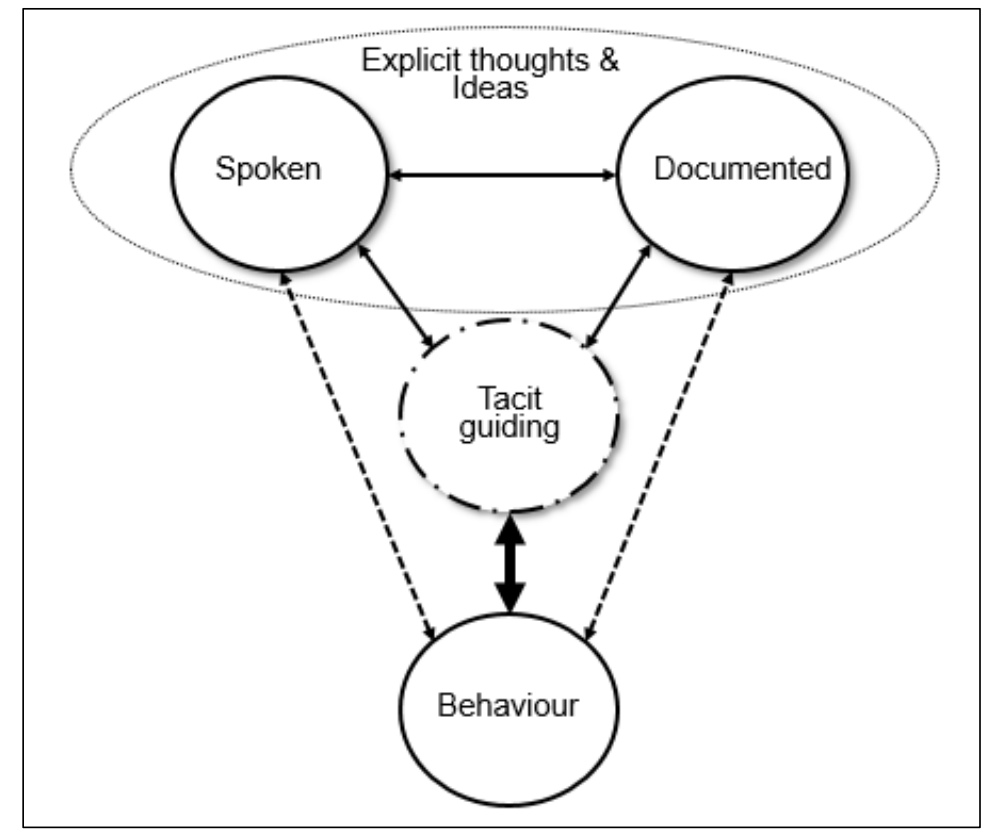

Figure 2 - Relationship between different manifestations of ideas and behaviour (adapted from Marmgren, Alänge and Book 2012)

The different parts of the framework are clarified below:

Spoken (or directly communicated): is normally direct verbal communication, but includes all direct communication and can also be through body language, writing or drawing on a whiteboard with the purpose of immediate communication. 
Documented (or indirectly communicated): is indirect communication and normally means texts and figures (e.g., organisational charts, process maps), but can also be recorded speeches, photos of whiteboards, and more.

Spoken and Documented are different manifestations of explicit ideas. There are many different (and often contradictory) explicit (sets of) ideas. Some are largely accepted by the organisation/group in focus, while others are not.

Tacit guiding: is the generally subconscious 'patterns' or 'tracks' in our brains that actually guide action in a specific situation whether it is about riding a bike, operating a production line or running a complex project. 'Tacit guiding' cannot be directly observed, but rather inferred by looking at action, or approached by in-depth interviewing.

Behaviour: is patterns of action that in principle can be observed.

In line with what was described in the Method section, several versions of this framework have been tested and used, partially depending on the context and the relative usefulness of different versions. ${ }^{4}$

\section{THE FRAMEWORK AS SENSITIZING DEVICE AND ANALYTICAL TOOL}

The framework has been used in many consulting projects, in action research projects and in the internal dialogue and development of Effort Consulting AB during half a decade. The purpose has varied and the framework is developing as we scrutinise the processes taking place in relation to the use of it.

One purpose of the conceptual framework is to serve as a 'sensitising device' (Weick, 1976, p.2) that will 'sensitise the observer to notice and question things that had previously been taken for granted'. The sensitising ability (in this case) is closely related to what Worren, Moore and Elliott (2002) call visual pragmatic validity. In our case, this refers to identifying corresponding aspects of the dynamics of an organisation. When the framework has been applied in dialogues (using Figure 2, or testing something closely corresponding) with professionals, the involved persons often experience that they develop a deepened understanding of prior experiences. We believe that this is due to it aiding in connecting subconscious and conscious thoughts in an interactive process, that is, the different parts of the model ${ }^{5}$.

Another related purpose of the framework is to serve as a tool for sensemaking (Weick, 1976). By giving new perspectives in organisations, it facilitated the

\footnotetext{
${ }^{4}$ One version, presented in Book, Marmgren and Gustafsson (2014), includes 'Unspoken' as another part of explicit thoughts and ideas. The purpose of this is to highlight the fact that some ideas might be explicit for some people/groups, though for different reasons not spoken of. 'Unspoken' is then shown with a dotted line to illustrate that it is not directly observable.

${ }^{5}$ Or System 1 and System 2 (Kahneman, 2011), or explicit and tacit knowledge (Nonaka, 1994).
} 
process of making sense of what was going on and how it influenced the development.

Three examples will serve us to exemplify how we have used the framework as a sensitising device. There are other ways to use it as well.

\section{Example 1: Use in a process management project}

In a global process management project in a large multinational company there was constant confusion in the terminology. The aim was to develop a truly process-oriented organisation; in practice, however, much of the attention was drawn to process maps and documentation rather than true process development. Processes were often discussed as if they were the maps rather than what was going on in reality. The implication of this misconception was probably a less action-oriented project than intended, with major efforts to map everything rather than to drive improvement. We used the framework (Figure 3) to graphically clarify the difference between what is documented and spoken and what is actually done, and that confused language risks confusing people (e.g., between improving maps and improving action/results).

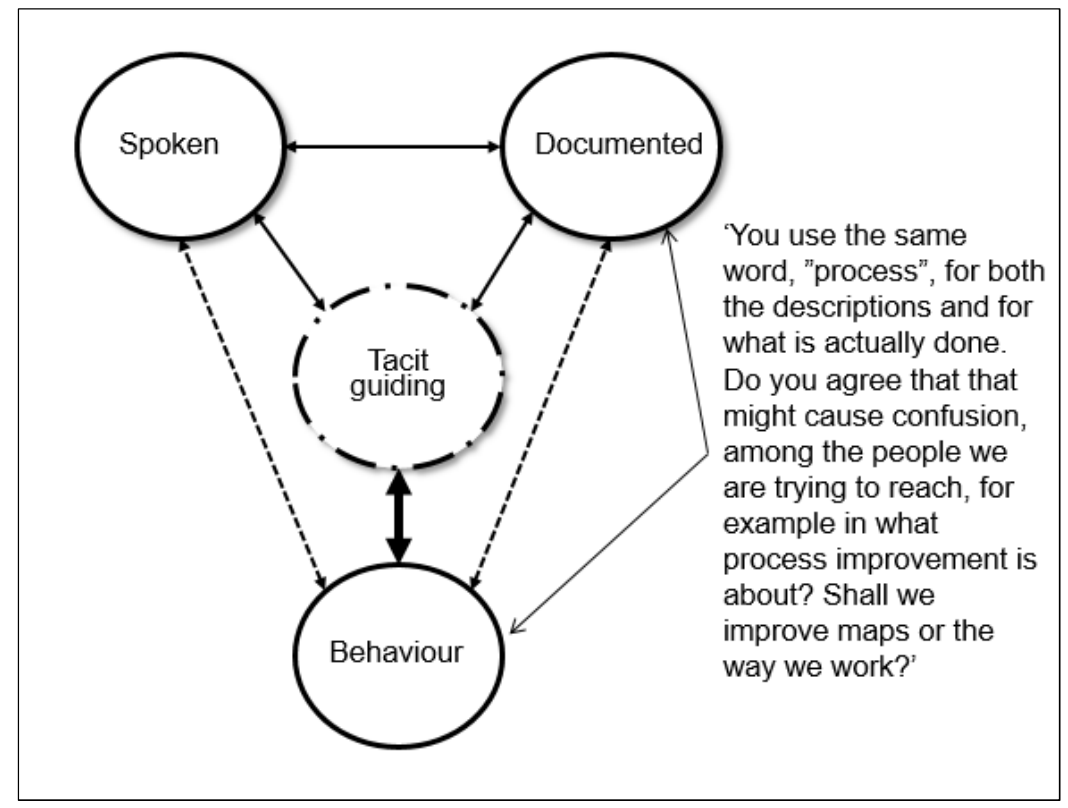

Figure 3 - Use in a process management project

\section{Example 2: Use in discussing competence development}

As part of a dialogue concerning the competence development at Effort Consulting, we used the framework (Figure 4) to clarify the competence development strategy. We agreed that classroom training is good, but even more important is teaming up in the projects and taking extra time for reflection and 
learning during the actual work in action. In that way we can adjust behaviour according to our reflections and reach better tacit guided action supported both by what is spoken, what is documented and through behaviour. In doing so, we get a tighter coupling between reflection and action, which stimulates action learning and more efficient and effective development towards improved competence. We were able to graphically clarify what actually drives changed behaviour, that the links from Spoken and Documented (e.g. classroom training) normally are comparatively weak, and that reflection in action is a powerful way of learning.

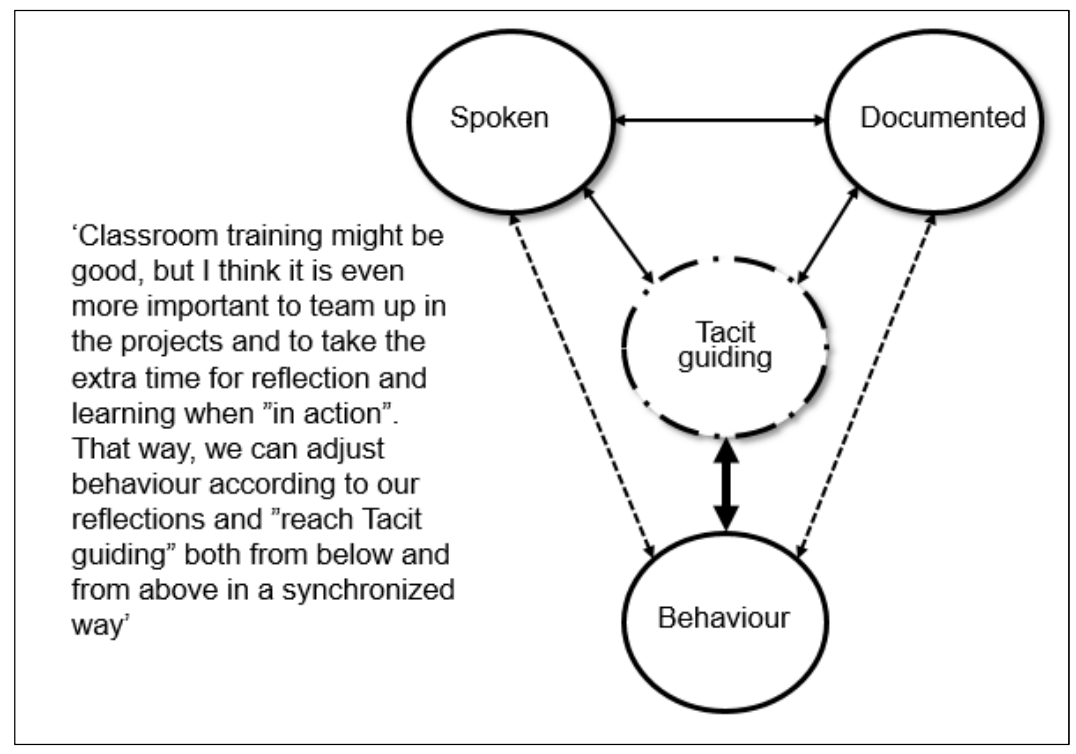

Figure 4 - Use in discussing competence development

\section{Example 3: Use in discussing quality in theory and in action}

In consultancy work, together with the top management team in a company within the marine industry, we needed to explain certain problematic patterns of organising that often take place in organisations. We were using the framework (Figure 5) when the CEO got inspired and explained that during daily operations they were in a combination of Tacit guiding and Behaviour, while when they were consciously discussing quality or operational development, they tended to work in the upper part of the model. A problem was that these two very different patterns of organising seldom met and complemented each other. Instead, the conscious work became ineffective, as it had minor influence on what actually guides work (Tacit guiding) and on work itself (Behaviour). In this example, the framework stimulated the CEO to express a core mechanism that was influencing the development of the firm. The framework offered a graphical background to the dialogue about the dynamic in the organisational system: 


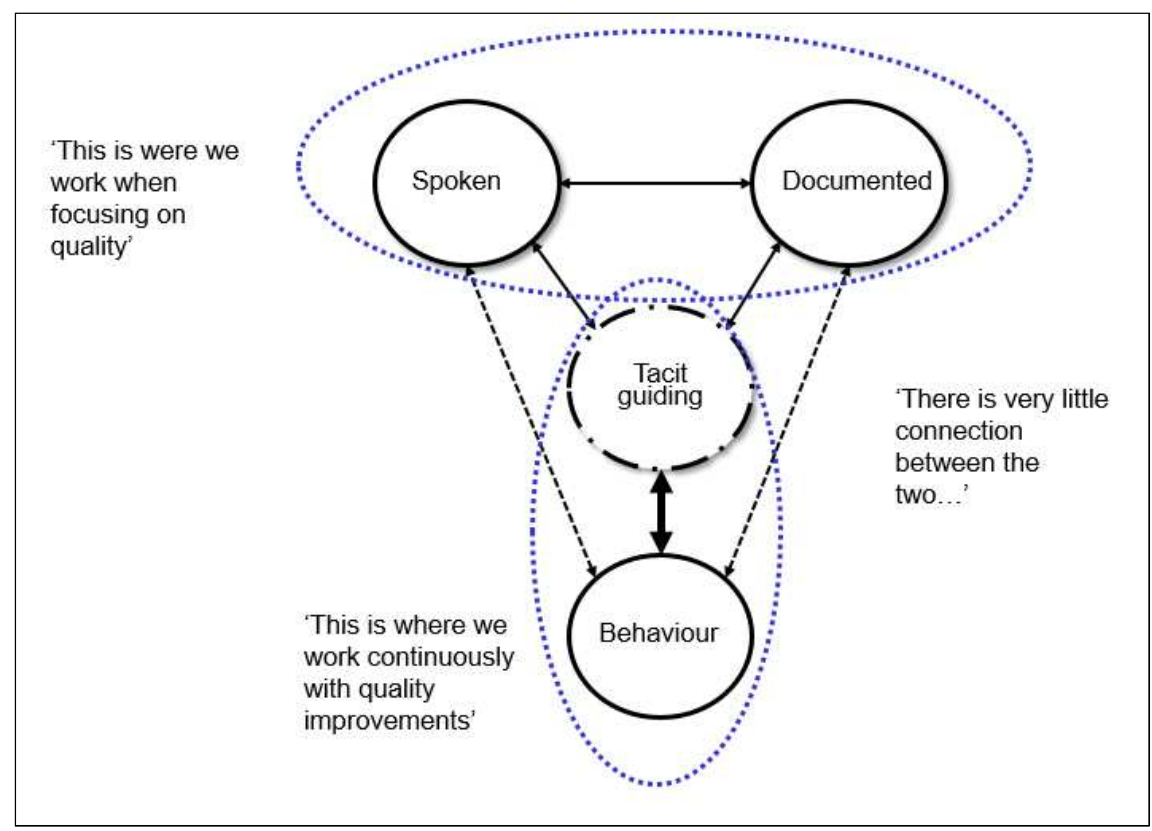

Figure 5 - Use in discussing quality in theory and in action

We (the authors) often observe how interviewees, customers, and co-workers get 'aha experiences' as we use the visual representation of the framework. This seems to be the case in particular for professionals with relevant experience in the management fields. Sometimes this happens at first glance with little or no explanation required. That it is so easy to relate to, at least for some professionals in the related fields, is also a sign of validity. The graphical framework functions as a sensitizing device by making them aware of disconnects between different components, and it aids in making tacit dimensions explicit and possible to scrutinize and develop. Thus, it connects the tacit knowledge to other more conscious aspects of an organisation, making it actionable.

The framework has also been used in empirical analyses of organisational change and its explanatory power has been validated by interviewees participating in the change processes: process management and quality systems (Marmgren, Alänge and Book, 2012); sustainability in product development (Alänge, Clancy and Marmgren, 2016); and sustainability strategies (Book, Marmgren and Gustafsson, 2014).

As indicated by the three examples above and the three references to empirical research, the framework can be applied in many different ways, including for analysing:

- Coherence and clarity of terminology used (e.g., concepts such as management innovation, process, management system; Example 1) 
- Coherence of ideas and norms: both between explicit ideas (spoken and documented) and behaviour (Example 3) and coherence for the entire system (Alänge, Clancy and Marmgren, 2016)

- Dynamics of the system: what couplings are weak/strong, which norms govern the dynamics, which spoken or documented words, or actions are of special importance in carrying certain ideas (Alänge, Clancy and Marmgren, 2016)

- Dynamics of specific initiatives (Example 3; Marmgren, Alänge and Book, 2012)

- Interactions between (sets of) ideas or different change initiatives (Marmgren, Alänge and Book, 2012)

- Conditions for driving change projects and implications for how to adapt these to improve the likelihood of success (Alänge, Clancy and Marmgren, 2016)

- Alternative courses of action and comparing their consequences (Example 2)

\section{THE POTENTIAL VALUE OF KNOWING AND USING THE CONCEPTUAL FRAMEWORK}

The conceptual framework can be of value both for academics and leaders in organisations.

The value of knowing the framework $^{6}$ is primarily that it functions as a sensitising device (Weick, 1976) that 'opens new eyes' to more clearly differentiate between the parts of the model. This means that problematic patterns become apparent that otherwise might have been missed. This includes the common confusion in language between integral parts of an organisation (processes, culture, management systems) and their descriptions ${ }^{7}$. It also includes the related problem of disconnection between improvement of explicit thoughts and ideas (often with a lot of focus on documentation), and of improvement of action and results ${ }^{8}$. It can also foster an understanding of what drives change in behaviour, and that documentation, or even classroom training ${ }^{9}$, have their limitations. In general, it gives a frame of reference for understanding, and talking about, how management ideas and documents interact with behaviour. The process of implementing new management initiatives is an important

\footnotetext{
${ }^{6}$ Knowing in this case, implies using it in your own thought processes (without drawing it), mostly initiated subconsciously, i.e., by System 1 (Kahneman, 2011).

${ }^{7}$ See Example 1 in the section 5 above.

${ }^{8}$ See Example 3 in the section 5 above.

${ }^{9}$ See Example 2 in the section 5 above.
} 
example of when this is relevant, but it is also of continuous relevance as in, for example, the use of documentation for supporting/controlling operations, which is something most organisations have in common, to some extent.

The value of using the framework is both as a tool for analysis and as a tool for communication, or the combination of both. Maybe the most important value in using the tool is its communicative power. It is our experience that in a specific context, it can give immediate insights in line with the value of knowing the framework presented above ${ }^{10}$. This seems to be the case in particular for people with relevant work experience that they can relate to the framework.

Using the framework for analysis makes it possible to further develop the intuitive understanding from knowing the framework. The graphical nature of the framework makes it easier for a team to make an analysis together or to adjust it in discussions with other stakeholders at later stages, both of which will support joint ownership and thereby the action resulting from the analysis. As a tool for analysis, it can be used in many different ways including variations in:

- Scope: e.g., the entire organisation, a unit/group or a project

- Time: analysing an existing state (or a retrospective timeline) or a possible change/project

- Comparative or not: focusing on one scope or comparing different ones (e.g., units or projects)

A list of specific possible uses is given in section 5. The framework as sensitizing device and analytical tool above, which also refers to articles and examples exemplifying these uses.

Knowing and using the framework also makes it easier to understand and use the general implications below, even though (in line with the framework) it is in no way a guarantee that they will be used.

\section{MANAGERIAL IMPLICATIONS}

One implication for leaders in all kinds of organisations, as indicated by the previous section, is that knowing and using the framework can be of considerable value. The framework, and the theory it builds on, also have general implications; in other words, these are independent of whether the framework is used or not. Some of the most important and clear implications are presented below.

\footnotetext{
${ }^{10}$ See Examples 1, 2 and 3 in the section 5 above.
} 
Clarity in communication: Leaders should try to avoid using language that risks confusion between the different parts of the framework as with, for example, process (action) with documentation, as this risks directing focus to the wrong thing (normally documentation). A common example of this is how the term management system is used in relationship to certifications (e.g., ISO 9001) or legal demands where it, in our experience, often is equated with a document manual, giving the work with the standard/certification a focus skewed towards documentation. ${ }^{11}$

Understanding the dynamic of your organisation/system: Leaders should try to be aware of the relevant dynamics of their organisations. What is it that guides behaviour? Is it a strong company culture? Professional culture? Documentation? Shared values/idealism? Personal gains? Other things? It is probably a combination of factors, but understanding the most important ones will make it easier to see what strengths to build on (and not undermine) as well as what measures will probably be futile. One example of this is the importance of nurturing a valuable culture, which otherwise might be rapidly compromised by actions that in another organisation might be considered acceptable. Another example of this is the role of (different kinds of) documentation, where the same type of document might be effective in one organisation but ineffective in another. $^{12}$

A related issue is the importance of coherence; in other words, it is important that what you say, write and do, will fit ('walking the talk'). Doing, in this case, also includes decisions on remuneration systems, or what is prioritized in meetings (e.g., management meeting agendas). If you as a leader say something is important in a speech and/or write a document about it (e.g., customer focus or gender equality), but do not prioritise discussing it in regular meetings and do not reward those who do prioritise it, this would be a clear lack of coherence. It would probably not only result in employees ignoring that spoken and/or written message, but also in weakening your ability to use those means for other messages. In a more general sense, lack of coherence risks confusing employees, damaging morale and weakening the ability to control/develop the organisation (rendering management efforts more inefficient). ${ }^{13}$

Implications for choosing a new concept or tools: The usage of new ideas like concepts and tools, sometimes packaged as a management initiative, is a common way to drive improvement. When choosing, the fit between the inherent logic of the new ideas and the dynamic of the organisation should be considered. Ideas generally need to be adapted to the local context in an iterative learning process, but if the fit is bad (but the ideas still considered useful), it is

\footnotetext{
${ }^{11}$ See Example 1 in the section 5 above.

12 Alänge, Clancy and Marmgren (2016) use the framework to give an example of how different cultures can both be effective but require different management.

${ }^{13}$ Marmgren, Alänge and Book (2012), and Alänge, Clancy and Marmgren (2016) use the framework to show the importance of coherence.
} 
recommended to start adapting them to the organisation's dynamic from the planning stage.

Understanding change as contextual and iterative: Since the planning and adaptation of the cultivation of a new management concept or tool is an iterative process, in itself adapting to an unfolding process of change ${ }^{14}$, it is important to set and communicate a clear purpose as well as not plan actions in too much detail in a long-term perspective. This is the case, since you will probably wish to adapt the plan to what happens. It is, however, recommended that you have a clear structure to drive the change (e.g., responsibilities, meetings) in order to keep driving and updating the plan.

The role of documentation: New policy statements, written procedures, and the like, often do not seem to have the impact intended. This seems to be the case in particular when documents are written to assure compliance with external demands (e.g., legal demands, ISO standards), where the management's intentions with the documentation often are not clear (i.e., lacking coherence). Leaders should therefore be aware of the limited possibility of using documents to change behaviour, and that it depends on the clarity of the message they send (coherence) and the general role/importance of documentation in their organisation (i.e., knowing your system). This importance can be changed, but that is an issue of cultural change, normally quite a slow process. The above reasoning, however, applies more strongly to descriptive or 'passive' documentation; in other words, to documentation that describes how to do something (or what values to hold), such as procedures, process maps policy statements, and so forth. Cultivating change through using operative or 'active' documentation, which are both (sometimes necessary/required) tools to achieve your task (e.g., templates, IT systems etc.), has a much greater chance of success.

The importance of learning in action ${ }^{15}$ and reflecting on action: Organisational development often focuses on learning through classroom training and documentation (books, procedures, etc.). This can be valuable, but including learning when doing will most likely increase the probability of changed behaviour. Learning when doing is something that happens subconsciously and continuously; however, what we refer to here is a learning that connects to the concepts and tools of organisational development (which could be something basic like a new written procedure or template). If you do not make this connection, you risk creating a theoretical organisational development in a conference room that has little impact on the actual development of how things

\footnotetext{
${ }^{14}$ To reach a significant change in 'Tacit guiding' with a management initiative, generally involves a context-specific iteration and learning between all parts of the model. What comes out in the end will be something specific to that context. Examples of this are given by Alänge, Clancy and Marmgren (2016), e.g., the adaptation of a tool for LCA to a different context.

15 Reflection-in-action is an important part of individual skilled professional behaviour as argued by Schön (1983). Here, we emphasize that this individual and often subconscious process need to become an explicit and interactive reflective group process.
} 
are done. ${ }^{16}$ In order to make this connection, it is important to call attention to the concepts and tools when conducting normal 'operations' (e.g., in regular meetings, in projects, on a production line, etc.). It is also important to be able to reflect on the usefulness of the tools, concepts and/or behaviours, as well as how to change these in order to improve results. ${ }^{17}$ To do this scheduled meetings (or parts of meetings) for reflection, preferably with an organisational development specialist present, could be used. Encouraging a culture of spontaneous reflection, and sufficient 'slack' in normal operations in order to facilitate this, should also be considered. One option to strongly support these kinds of reflection, is to have organisational development specialists 'embedded' in normal operations (e.g., on a project).

\section{CONCLUSION}

Leaders in today's society are facing complex challenges in the struggle for sustainable development in their organisations. New ideas are either forced by, for example, new requirements or changes in the law, or brought in by leaders in their efforts to stimulate development. Communication takes place on a variety of levels and through different channels. Not until behaviours are changed however, can the results and effects sought after become reality. We need tools to reflect on the process towards productive change with the aid of external or internal ideas that can facilitate success. This paper suggests a framework that has proven to function well in dialogues concerning such processes. We see great potential in developing the framework further and continue to apply it in various change projects.

For effective conscious quality oriented work to take place, all aspects of the model need to influence each other in a dynamic way that stimulates creative tension and development. The framework graphically highlights the relationship between explicit ideas (mainly manifested as spoken or documented) and 'tacit guiding' ideas, and that the latter is what largely controls action. It also implies that for new explicit ideas to become effective, which is normally the purpose of improvement initiatives, they have to become naturalised; in other words, they need to become part of the tacit guiding ideas. This is often quite difficult to achieve, as shown by the fact that most improvement initiatives tend to not give the intended results.

\footnotetext{
${ }^{16}$ See Example 3 in the section 5 above.

${ }^{17}$ See Example 2 in the section 5 above.
} 


\section{REFERENCES}

Alänge, S., 1992. Total Quality Management as a Tool for Organizational Change - The case of Motorola. CIM Working Papers, WP 1992:01.

Alänge, S., Jacobsson, S. and Jarnehammar, A., 1998. Some Aspects of An Analytical Framework for Studying the Diffusion of Organisational Innovations. Technology Analysis \& Strategic Management 10(1), pp.3-21.

Alänge, S., Clancy, G. and Marmgren, M., 2016. Naturalizing sustainability in product development: A comparative analysis of IKEA and SCA. Journal of Cleaner Production, 135, pp.1009-1022.

Alänge, S. and Mellby, C., 2006. Insider Action Research in Innovation Systems. In: C. Mellby, 2006. Agora Research: Design interventions in interorganizational settings. (lic. thesis) Chalmers University of Technology, Gothenburg.

Alänge, S. and Steiber, A., 2011. Diffusion of organisational innovations: An empirical test of an analytical framework. Technology Analysis \& Strategic Management 23(8), pp.881-897.

Argyris, C. and Schön, D.A., 1978. Organizational learning: A theory of action perspective (Vol. 173). Reading, MA: Addison-Wesley.

Argyris, C. and Schön, D., 1996. Organizational Learning II: Theory, Method and Practice. Reading, MA: Addison-Wesley.

Barley, S.R., 1986. Technology as an Occasion for Structuring: Evidence from Observations of CT Scanners and the Social Order of Radiology Departments. Administrative Science Quarterly, 31(1), pp.78-108.

Barnard, C.I., 1938. The Functions of the Executive. Cambridge, MA: Harvard University Press.

Beer, M., 2001. Why Management Research Findings Are Unimplementable: An Action Science Perspective. Reflections 2(3), pp.58-65.

Book, S., 2006. Naturalizing Quality Management: A Problem of Organizing in Processes of Change. PhD. Chalmers University of Technology, Dept. of Technology Management and Economics, Gothenburg.

Book, S., Alänge, S. and Solly, B., 2004. Quality Management from a Company Development Perspective: The complexity of a change process. Proceedings of the 7th International QMOD Conference Management Challenge of the New Millennium in Monterrey, Mexico, 4-6 August, 2004, pp.57-70.

Book, S., Marmgren, M. and Gustafsson, B., 2014. Sustainable governance: setting direction and inspiring change in a city development corporation. 18th International Conference on Sustainable Innovation, Copenhagen, Denmark, 3-4 November 2014.

Brannick, T. and Coghlan, D., 2007. In Defense of Being 'Native': The Case for Insider Academic Research. Organizational Research Methods 10(1), pp.59-74. 
Brunsson, N., 1982. The irrationality of action and action rationality: decisions, ideologies and organizational actions. Journal of Management Studies 19(1), pp.29-44.

Clancy, G., 2014. Assessing Sustainability and Guiding Development towards More Sustainable Products. PhD. Chemical Environmental Science, Dept. of Chemical and Biological Engineering, Chalmers University of Technology, Gothenburg.

Csikszentmihalyi, M., 1990. Flow: The Psychology of Optimal Experience. New York, NY: Harper.

De Guerre, D.W., 2002. Doing action research in one's own organization: An ongoing conversation over time. Systemic Practice and Action Research 15(4), pp.331-349.

Dubois, A. and Gadde, L.-E., 2002. Systematic combining: an abductive approach to case research. Journal of business research 55(7), pp.553-560.

Friberg, M., 1975 and 1976. Är lönen det enda som sporrar oss att arbeta? (Is salary the only incentive for work? - our transl. from Swedish). Sociologisk Forskning, 1975(4), pp.52-65 and 1976(1), pp.24-42.

Frischer, J., 2006. The learning alliance: relational aspects of learning. PhD. Department of Communication and Psychology, Aalborg University, Aalborg.

Gummesson, E., 2000. Qualitative Methods in Management Research. 2nd ed., Thousand Oaks, CA: Sage.

Johnson-Laird, P.N., 1983. Mental Models: Towards a Cognitive Science of Language, Inference, and Consciousness. Boston, MA: Harvard University Press.

Kahneman, D., 2011. Thinking, Fast and Slow. London: Penguin Books (in 2012).

Karlsson, U., 1979. Alternativa Produktionssystem till Lineproduktion: En utvärdering av produktionssystem $i$ karossverkstaden vid SAAB-SCANIA Trollhättan. PhD. Department of Sociology, University of Gothenburg, Gothenburg.

Keating, E., Oliva, R., Repenning, N., Rockart, S. and Sterman, J., 1999. Overcoming the Improvement Paradox. European Management Journal 17(2), pp.120-134.

Lifvergren, S., 2013. Quality Improvement in Healthcare: Experiences from two longitudinal case studies using an action research approach. PhD. Dept. of Technology Management and Economics, Chalmers University of Technology, Gothenburg.

March, J.G. and Olsen, J.P. eds., 1976. Ambiguity and Choice in Organizations. Bergen: Universitetsforlaget. 
Marmgren, M., Alänge, S. and Book, S., 2012. Understanding management systems: A test of a conceptual framework. $15^{\text {th }}$ International $Q M O D$ Conference, 6-9 September, Poznan, Poland.

Meyer, J.W. and Rowan B., 1977. Institutionalized Organizations: Formal Structure as Myth and Ceremony. The American Journal of Sociology 83(2), pp.340-363.

Nadler, D.A. and Tushman, M.L., 1997. Implementing New Designs: Managing Organizational Change. In: Tushman, M.L. and Anderson, P. eds., 1997. Managing Strategic Innovation and Change. New York, NY: Oxford University Press, pp.595-606.

Nonaka, I., 1994. A Dynamic Theory of Organizational Knowledge Creation. Organization Science 5(1), pp.14-37.

Polanyi, M., 1966. The Logic of Tacit Inference. Philosophy 41(155), pp.1-18.

Schein, E.H., 1984. Coming to a New Awareness of Organizational Culture. Sloan Management Review 25(2), pp.3-16.

Schumpeter, J.A., 1934. The Theory of Economic Development: An Inquiry into Profits, Capital, Credit, Interest, and the Business Cycle. Cambridge, MA: Harvard University Press.

Schön, D.A., 1983. The Reflective Practitioner: How Professionals Think in Action. New York, NY: Basic Books.

Simon, H.A., 1992. What is an Explanation of Behavior? Psychological Science, 3(3), pp.150-161.

Steiber A. and Alänge, S., 2013. A corporate system for continuous innovation: The case of Google Inc. European Journal of Innovation Management, 16(2), pp.243-264.

Steiber, A. and Alänge, S., 2016. The Silicon Valley Model - Management for Entrepreneurship. Cham: Springer International.

Tversky, A. and Kahneman, D., 1974. Judgement under uncertainty: Heuristics and Biases. Science, 185(4157) (republished as Appendix A, pp.421-432 in Kahneman, 2011)

Tushman, M. and O’Reilly III, C., 1997. Winning through Innovation: A Practical guide to Leading Organizational Change and Renewal. Boston, MA: Harvard Business School Press.

Weick, K., 1976. Educational organizations as loosely coupled systems. Administrative Science Quarterly 21(1), pp.1-19.

Weick, K., 1995 Sensemaking in Organizations. Thousand Oaks, CA: Sage.

Worren, N.A., Moore, K. and Elliott, R., 2002. When theories become tools: Toward a framework for pragmatic validity. Human Relations 55(10), pp.12271250. 


\section{ABOUT THE AUTHORS}

Magnus Marmgren, MSc, Partner Effort Consulting, Gothenburg, Sweden.

$\mathrm{PhD}$ candidate Division of Science, Technology and Society, Dept. of Technology Management and Economics, Chalmers University of Technology, email: magnus.marmgren@effort.se

Sverker Alänge, Associate professor, Division of Science, Technology and Society, Dept. of Technology Management and Economics, Chalmers University of Technology, Gothenburg, Sweden, email: sverker.alange@ chalmers.se

Stefan Book, PhD, Partner and CEO Effort Consulting, Gothenburg, Sweden, email: stefan.book@effort.se 